\title{
Prediction Acidity Constant of Various Benzoic Acids and Phenols in Water Using Linear and Nonlinear QSPR Models
}

\author{
Aziz Habibi-Yangjeh, "Mohammad Danandeh-Jenagharad, and Mahdi Nooshyar \\ Department of Chemistry, Faculty of Science, University of Mohaghegh Ardebili, P.O. Box 179, Ardebil, Iran \\ *E-mail:habibiyangjeh@yahoo.com; ahabibi@uma.ac.ir \\ Received April 18, 2005
}

\begin{abstract}
An artificial neural network (ANN) is successfully presented for prediction acidity constant ( $\mathrm{pKa}$ ) of various benzoic acids and phenols with diverse chemical structures using a nonlinear quantitative structure-property relationship. A three-layered feed forward ANN with back-propagation of error was generated using six molecular descriptors appearing in the multi-parameter linear regression (MLR) model. The polarizability term $\left(\pi_{\mathrm{l}}\right)$, most positive charge of acidic hydrogen atom $\left(\mathrm{q}^{+}\right)$, molecular weight $(\mathrm{MW})$, most negative charge of the acidic oxygen atom $\left(\mathrm{q}^{-}\right)$, the hydrogen-bond accepting ability $\left(\varepsilon_{\mathrm{B}}\right)$ and partial charge weighted topological electronic (PCWTE) descriptors are inputs and its output is $\mathrm{pKa}$. It was found that properly selected and trained neural network with 205 compounds could fairly represent dependence of the acidity constant on molecular descriptors. For evaluation of the predictive power of the generated ANN, an optimized network was applied for prediction $\mathrm{pKa}$ values of 37 compounds in the prediction set, which were not used in the optimization procedure. Squared correlation coefficient $\left(\mathrm{R}^{2}\right)$ and root mean square error (RMSE) of 0.9147 and 0.9388 for prediction set by the MLR model should be compared with the values of 0.9939 and 0.2575 by the ANN model. These improvements are due to the fact that acidity constant of benzoic acids and phenols in water shows nonlinear correlations with the molecular descriptors.
\end{abstract}

Key Words : Quantitative structure-property relationship, Artificial neural networks, Acidity constant, Phenols, Benzoic acids

\section{Introduction}

The macroscopic (bulk) activities/properties of chemical compounds clearly depend on their microscopic (structural) characteristics. Development of quantitative structure-property/activity relationships (QSPR/QSAR) on theoretical descriptors is a powerful tool not only for prediction of the chemical, physical and biological properties/activities of compounds, but also for deeper understanding of the detailed mechanisms of interactions in complex systems that predetermine these properties/activities. ${ }^{1-10}$ QSPR/QSAR models are essentially calibration models in which the independent variables are molecular descriptors that describe the structure of the molecules and the dependent variable is the property or activity of interest. Since these theoretical descriptors are determined solely from computational methods, a priori predictions of the properties/activities of compounds are possible, no laboratory measurements are needed thus saving time, space, materials, equipment and alleviating safety (toxicity) and disposal concerns. An enormous number of descriptors have been used by researchers to increase the ability to correlate biological, chemical and physical properties. To obtain a significant correlation, it is crucial that appropriate descriptors be employed. ${ }^{11,12}$

Various methods for constructing QSPR/QSAR models have been used including multi-parameter linear regression (MLR), principal component analysis (PCA) and partial least-squares regression (PLS). ${ }^{13-16}$ In some cases, it is more convenient that a linear relationship between property/ activity and descriptors is considered. If there is not a welldefined linear relationship, the discussed method cannot give a perfect QSPR/QSAR model. Artificial neural networks (ANNs) are capable of recognizing highly nonlinear relationships. ${ }^{17-20}$ ANNs are biologically inspired computer programs designed to simulate the way in which the human brain processes information. ANNs gather their knowledge by detecting the patterns and relationships in data and learned (or trained) through experience, not from programming. There are many types of neural networks designed by now and new ones are invented every week. ${ }^{20}$ The behavior of a neural network is determined by transfer functions of its neurons, by learning rule, and by the architecture itself. An ANN is formed from artificial neuron or processing elements (PE), connected with coefficients (weights), which constitute the neural structure and are organized in layers. The first layer is termed the input layer, and the last layer is the output layer. The layers of neurons between the input and output layers are called hidden layers. Neural networks do not need on explicit formulation of the mathematical or physical relationships of the handled problem. These give ANNs an advantage over traditional fitting methods for some chemical application. For these reason in recent years, ANNs have been used to a wide variety of chemical problems such as simulation of mass spectra, ion interaction chromatography, aqueous solubility and partition coefficient, simulation of nuclear magnetic resonance spectra, prediction of bioconcentration factor, solvent effects on reaction rate and prediction of normalized polarity parameter 
in mixed solvent systems. ${ }^{21-36}$

It has been shown that the acid-base properties affect the toxicity, chromatographic retention behavior and pharmaceutical properties of organic acids and bases. ${ }^{37,38}$ On the other hand, interpretation and prediction of $\mathrm{pKa}$ values for chemical compounds are of general importance and usefulness for chemists. ${ }^{39}$ Although in the last years several theoretical studies have been performed for correlation of $\mathrm{p} K \mathrm{a}$ values with molecular parameters, but in these studies linear equations have been used. ${ }^{38-46}$

The main aim of present work is to develop a linear and nonlinear QSPR models based on molecular descriptors for prediction $\mathrm{pKa}$ values of various benzoic acids and phenols with diverse chemical structures (including 242 compounds).

\section{Theory}

A detailed description of theory behind a neural network has been adequately described by different researchers. ${ }^{17-19}$ There are many types of neural network architectures, but the type that has been most useful for QSAR/QSPR studies is the multilayer feed - forward network with back-propagation (BP) learning rule. ${ }^{20}$ The number of neurons in the input and output layers are defined by system's properties. The number of neurons in the hidden layer could be considered as an adjustable parameter, which should be optimized. The input layer receives the experimental or theoretical information. The output layer produces the calculated values of dependent variable. The use of ANNs consists of two steps: "training" and "prediction". In the training phase the optimum structure, weight coefficients and biases are searched for. These parameters are found from training and validation data sets. After the training phase, the trained network can be used to predict (or calculate) the outputs from a set of inputs. ANNs allow one to estimate relationships between input variables and one or several output dependent variables. The ANN reads the input and target values in the training data set and changes the values of the weighted links to reduce the difference between the calculated output and target values. The error between output and target values is minimized across many training cycles until network reaches specified level of accuracy. If a network is left to train for too long, however, it will overtrain and will lose the ability to generalize. ${ }^{22-36}$

\section{Experimental Section}

Descriptor generation. The derivation of theoretical molecular descriptors proceeds from the chemical structure of the compounds. In order to calculate the theoretical descriptors, the z-matrices (molecular models) were constructed with the aid of HyperChem 7.0 and molecular structures were optimized using AM1 algorithm. ${ }^{47}$ In order to calculate some of theoretical descriptors, the molecular geometries of molecules were further optimized with the same algorithm in MOPAC program version 6.0. The other molecular electronic descriptors were calculated by Dragon package version $2.1{ }^{48}$ For this propose the output of the HyperChem software for each compound feed into the Dragon program and the descriptors were calculated. As a result, a total of 18 theoretical descriptors were calculated for each compound in the data sets (242 compounds).

Linear correlations. Acidity constant of benzoic acids and phenols are literature values at $25{ }^{\circ} \mathrm{C} .{ }^{49}$ MLR model was developed for prediction of $\mathrm{pKa}$ values by molecular descriptors. The method of stepwise multi-parameter linear regression was used to select the most important descriptors and to calculate the coefficients relating the $\mathrm{pKa}$ to the descriptors. The MLR models were generated using spss/pc software package release 9.0.

Neural network generation. The specification of a typical neural network model requires the choice of the type of inputs, the number of hidden layers, the number of neurons in each hidden layer and the connection structure between the inputs and the output layers. The number of input nodes in the ANNs was equal to the number of molecular descriptors in the MLR model. A three-layer network with a sigmoidal transfer function was designed. The initial weights were randomly selected between 0 and 1 . Before training, the input and output values were normalized between 0.1 and 0.9. The optimization of the weights and biases was carried out according to the resilient backpropagation algorithm. ${ }^{50}$ The data set was randomly divided into three groups: a training set, a validation set and a prediction set consisting of 168,37 and 37 molecules, respectively. The training and validation sets were used for the model generation and the prediction set was used for evaluation of the generated model, because a prediction set is a better estimator of the ANN generalization ability than a validation (monitoring) set. ${ }^{51}$

The performances of training, validation and prediction of ANNs are evaluated by the mean percentage deviation (MPD) and root-mean square error (RMSE), which are defined as follows:

$$
\begin{aligned}
\operatorname{MPD} & =\frac{1}{N} \sum_{i=1}^{N}\left|\frac{\left(P_{i}^{\exp }-P_{i}^{c a l}\right)}{P_{i}^{\exp }}\right| \\
\mathrm{RMSE} & =\sqrt{\sum_{i=1}^{N} \frac{\left(P_{i}^{\exp }-P_{i}^{c a l}\right)^{2}}{N}}
\end{aligned}
$$

where $P_{i}^{\exp }$ and $P_{i}^{c a l}$ are experimental and calculated values of $\mathrm{pKa}$ with the models and $N$ denote the number of data points.

Individual percent deviation (IPD) is defined as follows:

$$
\mathrm{IPD}=100 \times\left(\frac{P_{i}^{\text {calc }}-P_{i}^{\mathrm{exp}}}{P_{i}^{\exp }}\right)
$$

The processing of the data was carried using Matlab 6.5. ${ }^{52}$ The neural networks were implemented using Neural Network Toolbox Ver. 4.0 for Matlab. ${ }^{50}$ 


\section{Results and Discussion}

A major challenge in the development of MLR equations is connected with the possible multicollinearity of molecular descriptors. In order to decrease the redundancy existed in the descriptors data matrix, the correlation of descriptors with each other and with $\mathrm{pKa}$ of the compounds was examined and collinear descriptors were detected $(r>0.85)$. Among the collinear descriptors, one with the lowest correlation with the property was removed from the data matrix. Table 1 demonstrates that all of the descriptors are strongly orthogonal which reflects the statistical reliability of the model.

Multi-parameter linear correlation of $\mathrm{pKa}$ values of 168 benzoic acids and phenols versus the molecular descriptors in the training set gives the results in Table 2. It can be seen from this table that six descriptors are appeared in the MLR model. These descriptors are: polarizability index $\left(\pi_{\mathrm{I}}\right)$, most positive charge of acidic hydrogen atom $\left(\mathrm{q}^{+}\right)$, molecular weight (MW), most negative charge of acidic oxygen atom $\left(\mathrm{q}^{-}\right)$, the hydrogen-bond accepting ability $\left(\varepsilon_{\mathrm{B}}\right)$ and partial charge weighted topological electronic (PCWTE) descriptors.

The negative coefficient for $\pi_{\mathrm{I}}, \mathrm{q}^{+}, \mathrm{q}^{-}$and MW descriptors indicate that with increasing these descriptors, acidity constant $(\mathrm{Ka})$ increases. With increasing $\mathrm{q}^{+}$and $\mathrm{q}^{-}$of the compounds, interactions of water molecules with acidic hydrogen and oxygen of the compounds increase, then acidic hydrogen can be easily removed from the compounds. Polarizability and then the dipole-induced dipole interactions increase with increasing $\pi_{\mathrm{I}}$ and $\mathrm{MW}$, as a result acidity of the compounds increases with increasing these descrip-

Table 1. Correlation coefficients between various theoretical descriptors that have been used in the multi-parameter linear regression (MLR) and artificial neural network (ANN) models

\begin{tabular}{ccccccc}
\hline Descriptor & $\pi_{\mathrm{I}}$ & $\mathrm{q}^{+}$ & $\mathrm{q}^{-}$ & $\varepsilon_{\mathrm{B}}$ & MW & PCWTE \\
\hline$\pi_{\mathrm{I}}$ & 1 & 0.530 & 0.042 & 0.150 & 0.329 & 0.285 \\
$\mathrm{q}^{+}$ & 0.530 & 1 & 0.642 & 0.546 & 0.368 & 0.070 \\
$\mathrm{q}^{-}$ & 0.042 & 0.642 & 1 & 0.236 & 0.155 & 0.018 \\
$\varepsilon_{\mathrm{B}}$ & 0.150 & 0.546 & 0.236 & 1 & 0.248 & 0.038 \\
MW & 0.329 & 0.368 & 0.155 & 0.248 & 1 & 0.237 \\
PCWTE & 0.285 & 0.070 & 0.018 & 0.038 & 0.237 & 1 \\
\hline
\end{tabular}

tors. ${ }^{53}$ Acidity constant of the compounds decrease with increasing $\varepsilon_{\mathrm{B}}$ and PCWTE descriptors, because basicity of phenolic oxygen atom increases with increasing these descriptors. Effects of $\pi_{\mathrm{I}}, \mathrm{q}^{+}$and $\mathrm{MW}$ on $\mathrm{pKa}$ are higher than that of the other descriptors, because standardized coefficients of $\pi_{\mathrm{I}}, \mathrm{q}^{+}$and MW are higher than those of the other descriptors.

The calculated values of $\mathrm{pKa}$ for the compounds in training, validation and prediction sets using the MLR model have been plotted versus the experimental values of it in Figure 1.

The next step in this work was generation of the ANN model. There are no rigorous theoretical principles for choosing the proper network topology; so different structures were tested in order to obtain the optimal hidden neurons and training cycles. ${ }^{36}$ Before training the network, the number of nodes in the hidden layer was optimized. In order to optimize the number of nodes in the hidden layer, several training sessions were conducted with different numbers of hidden nodes. The root mean squared error of training (RMSET) and validation (RMSEV) sets were obtained at various iterations for different number of neu-

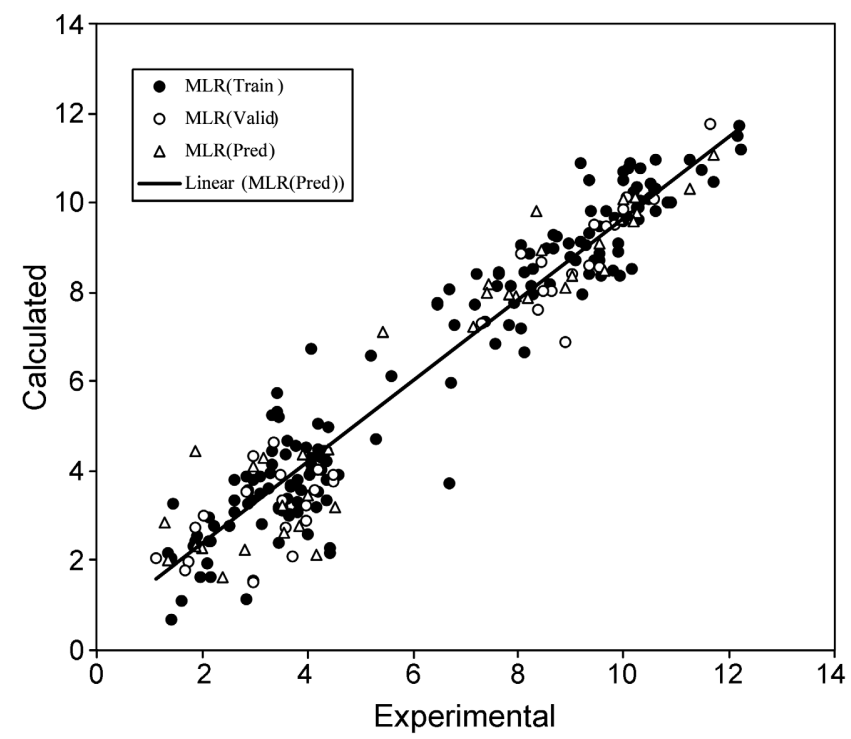

Figure 1. Plot of the calculated values of $\mathrm{pKa}$ from the MLR model versus the experimental values of it for training, validation and prediction sets.

Table 2. Descriptors, symbols and results of the multi-parameter linear regression (MLR) model ${ }^{a}$

\begin{tabular}{|c|c|c|c|c|}
\hline No. & Descriptor & Symbol & Coefficient & $\beta$ \\
\hline 1 & polarizability term & $\pi_{\mathrm{I}}$ & -8.361 & 0.080 \\
\hline 2 & most positive charge of acidic hydrogen atom & $\mathrm{q}^{+}$ & -110.471 & 0.521 \\
\hline 3 & molecular weight & MW & -0.0051 & 0.074 \\
\hline 4 & most negative charge of the phenolic oxygen atom & $q^{-}$ & -26.394 & 0.321 \\
\hline 5 & the hydrogen-bond accepting ability & $\varepsilon_{\mathrm{B}}$ & 34.445 & 0.080 \\
\hline 6 & partial charge weighted topological electronic & PCWTE & 0.0902 & 0.101 \\
\hline 7 & constant & & 42.278 & \\
\hline
\end{tabular}

$a_{\text {The }} \beta$ is standardized coefficient of descriptors. The polarizability term $\left(\pi_{\mathrm{I}}\right)$ is obtained by dividing the polarizability volume by the molecular volume The $\varepsilon_{\mathrm{B}}$ is equal $0.3-0.01\left(\mathrm{E}_{\mathrm{lw}}-\mathrm{E}_{\mathrm{h}}\right)$, in which $\mathrm{E}_{\mathrm{lw}}$ and $\mathrm{E}_{\mathrm{h}}$ are referring to the LUMO energy for water and HOMO energy for the compound, respectively. 


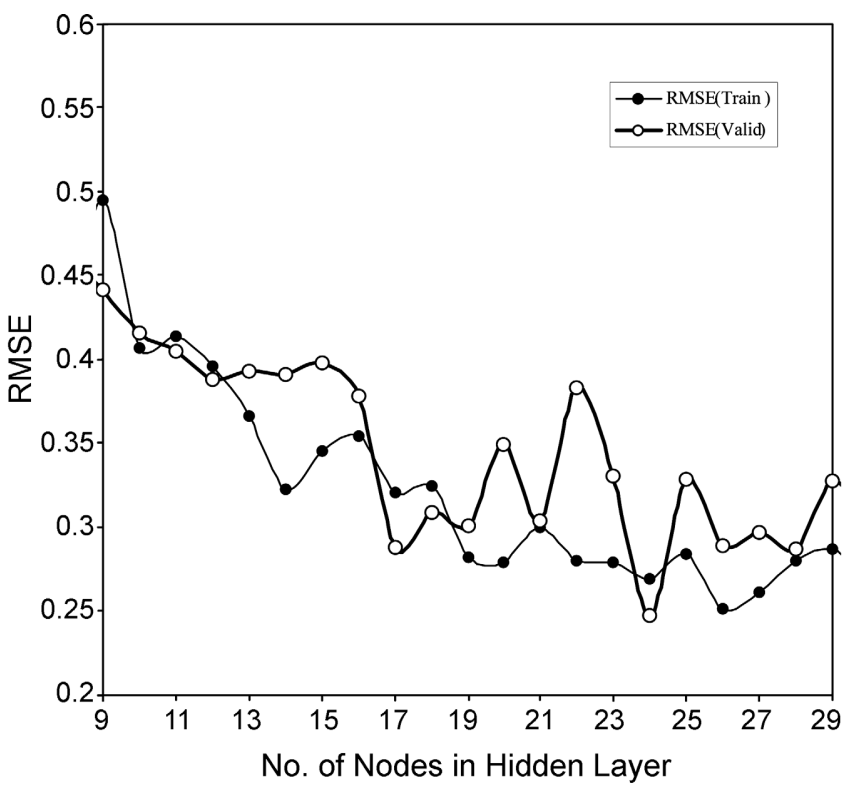

Figure 2. Plot of RMSE for training and validation sets versus the number of nodes in hidden layer.

rons at the hidden layer and the minimum value of RMSEV was recorded as the optimum value. Plot of RMSET and RMSEV versus the number of nodes in the hidden layer has been shown in Figure 2. It is clear that the twenty-four nodes in hidden layer is optimum value.

The six descriptors appearing in the MLR model (including $\pi_{\mathrm{I}}, \mathrm{q}^{+}, \mathrm{MW}, \mathrm{q}^{-}, \varepsilon_{\mathrm{B}}$, and PCWTE descriptors) were considered as inputs for developing the ANN. Then an ANN with architecture 6-24-1 was generated. It is note worthy that training of the network was stopped when the RMSEV started to increases i.e. when overtraining begins. The overtraining causes the ANN to loose its prediction power. ${ }^{34,36}$ Therefore, during training of the networks, it is desirable that

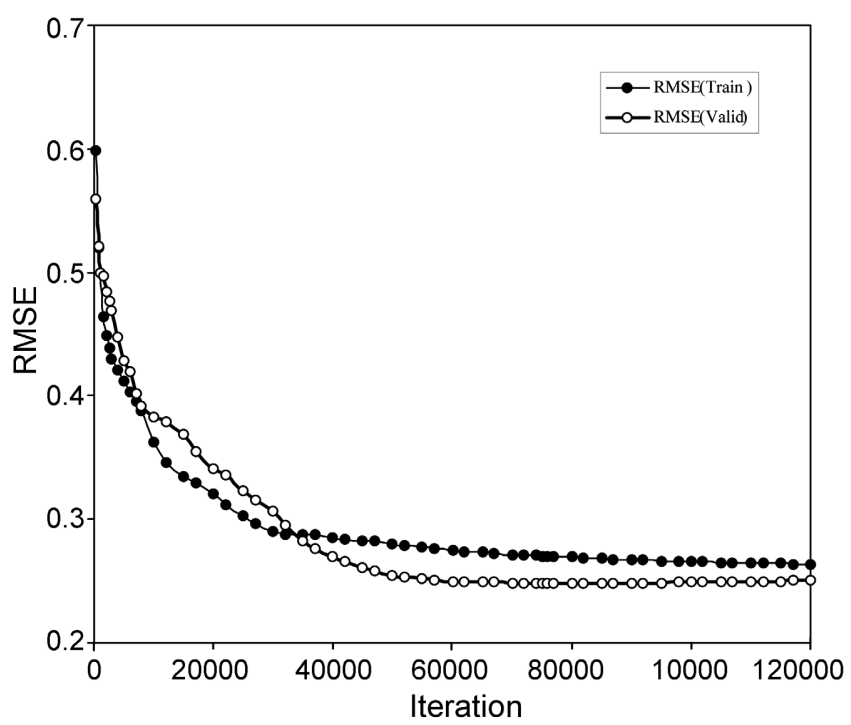

Figure 3. Plot of RMSE for training and validation sets versus the number of iterations. iterations are stopped when overtraining begins. To control the overtraining of the network during the training procedure, the values of RMSET and RMSEV were calculated and recorded to monitor the extent of the learning in various iterations. Results obtained showed that after 77000 iterations the value of RMSEV started to increase very little and overfitting slightly began (Figure 3 ).

The generated ANN was then trained using the training and validation sets for the optimization of the weights and biases. For the evaluation of the predictive power of the generated ANN, an optimized network was applied for prediction of the $\mathrm{pKa}$ values of the compounds in the prediction set, which were not used in the modeling procedure (Table 3). The calculated values of $\mathrm{pKa}$ for the compounds in training, validation and prediction sets using the ANN model have been plotted versus the experimental values of it in Figure 4.

As expected, the calculated values of $\mathrm{pKa}$ are in good agreement with those of the experimental values. The correlation equation for all of the calculated values of $\mathrm{pKa}$ from the ANN model and the experimental values is as follows:

$$
\mathrm{p} K \mathrm{a}(\mathrm{cal})=0.99299 \mathrm{pKa}(\exp )+0.04454
$$

$\left(\mathrm{R}^{2}=0.9931 ; \mathrm{MPD}=4.5044 ; \mathrm{RMSE}=0.2648 ; \mathrm{F}=34295.94\right)$

Similarly, the correlation of $\mathrm{pKa}$ (cal) versus $\mathrm{pKa}$ (exp) values in the prediction set gives equation (5):

$$
\mathrm{p} K \mathrm{a}(\mathrm{cal})=1.01212 \mathrm{p} K \mathrm{a}(\exp )-0.08200
$$

$\left(\mathrm{R}^{2}=0.9939 ; \mathrm{MPD}=5.0361 ; \mathrm{RMSE}=0.2575 ; \mathrm{F}=5718.11\right)$

Plot of IPD for $\mathrm{pKa}$ values in the prediction set versus the experimental values of it has been illustrated in Figure 5. As can be seen, the model did not show proportional and systematic error, because the slope $(\mathrm{a}=1.01212)$ and intercept $(b=-0.08200)$ of the correlation equation are not significantly different from unity and zero, respectively and the propagation of errors in both sides of zero is random (Figure 5).

Table 4 compares the results obtained using the MLR and ANN models. The squared correlation coefficient $\left(\mathrm{R}^{2}\right)$ and RMSE of the models for total, training, validation and prediction sets show potential of the ANN model for prediction of $\mathrm{pKa}$ values of various benzoic acids and phenols in water with one model.

As a result, it was found that properly selected and trained neural network could fairly represent dependence of the acidity constant of benzoic acids and phenols in water on the molecular descriptors. Then the optimized neural network could simulate the complicated nonlinear relationship between $\mathrm{pKa}$ values and the molecular descriptors. It can be seen from Table 4 that although the parameters appearing in the MLR model are used as inputs for the generated ANN, the statistics is shown a large improvement. These improvements are due to the fact that $\mathrm{pKa}$ values of the compounds show nonlinear correlations with the molecular descriptors. 
Table 3. Experimental and calculated values of $\mathrm{pKa}$ for various benzoic acids and phenols in water at $25{ }^{\circ} \mathrm{C}$ for training, validation and prediction sets by multi-parameter linear regression (MLR) and artificial neural network (ANN) models along with individual percent deviation (IPD) ${ }^{a}$

\begin{tabular}{|c|c|c|c|c|c|c|}
\hline No. & Compound & Exp. & MLR & $\mathrm{IPD}_{\mathrm{MLR}}$ & ANN & $\mathrm{IPD}_{\mathrm{ANN}}$ \\
\hline & Training set & & & & & \\
\hline 1 & 2-acetylphenol & 9.19 & 10.867 & 18.25 & 9.272 & 0.89 \\
\hline 2 & 4-acetylphenol & 8.05 & 9.05 & 12.42 & 8.794 & 9.24 \\
\hline 3 & 2-allylphenol & 10.28 & 9.637 & -6.25 & 9.972 & -3.00 \\
\hline 4 & 4-bromophenol & 9.34 & 8.42 & -9.85 & 9.126 & -2.29 \\
\hline 5 & 2,6-di-tert-butyl-4-bromophenol & 10.83 & 10.011 & -7.56 & 10.975 & 1.34 \\
\hline 6 & 2,6-di-tert-butyl-4-methylphenol & 12.23 & 11.201 & -8.41 & 11.983 & -2.02 \\
\hline 7 & 2,6-di-tert-butyl-4-methoxyphenol & 12.15 & 11.484 & -5.48 & 11.936 & -1.76 \\
\hline 8 & 2-tert-butylphenol & 11.24 & 10.96 & -2.49 & 10.752 & -4.34 \\
\hline 9 & 3-tert-butylphenol & 10.1 & 10.773 & 6.66 & 10.504 & 4.00 \\
\hline 10 & 4-tert-butylphenol & 10.31 & 10.768 & 4.44 & 10.788 & 4.64 \\
\hline 11 & 1-chloro-2,6-dimethyl-4-hydroxybenzene & 9.549 & 9.476 & -0.76 & 9.944 & 4.14 \\
\hline 12 & 4-chloro-2-nitrophenol & 6.48 & 7.724 & 19.20 & 6.475 & -0.08 \\
\hline 13 & 2-chlorophenol & 8.55 & 8.974 & 4.96 & 8.117 & -5.06 \\
\hline 14 & 3-chlorophenol & 9.10 & 8.72 & -4.18 & 8.971 & -1.42 \\
\hline 15 & 4-chlorophenol & 9.43 & 8.725 & -7.48 & 9.03 & -4.24 \\
\hline 16 & $o$-cresol & 10.26 & 9.875 & -3.75 & 10.174 & -0.84 \\
\hline 17 & 4-cyano-2,6-dimethylphenol & 8.27 & 7.934 & -4.06 & 7.872 & -4.81 \\
\hline 18 & 4-cyano-3,5-dimethylphenol & 8.21 & 8.869 & 8.03 & 8.033 & -2.16 \\
\hline 19 & 3-cyanophenol & 8.61 & 8.168 & -5.13 & 8.2 & -4.76 \\
\hline 20 & 3,5-dibromophenol & 8.056 & 7.186 & -10.80 & 8.024 & -0.40 \\
\hline 21 & 2,4-dichlorophenol & 7.85 & 8.141 & 3.71 & 7.96 & 1.40 \\
\hline 22 & 2,6-dichlorophenol & 6.78 & 7.264 & 7.14 & 6.827 & 0.69 \\
\hline 23 & 3,5-diethoxyphenol & 9.370 & 9.813 & 4.73 & 9.529 & 1.70 \\
\hline 24 & 3-(diethoxyphosphinyl)phenol & 8.68 & 9.267 & 6.76 & 8.628 & -0.60 \\
\hline 25 & 4-(diethoxyphosphinyl)phenol & 8.28 & 8.517 & 2.86 & 8.276 & -0.05 \\
\hline 26 & 3,4-dihydroxybenzaldehyde & 7.55 & 6.84 & -9.40 & 7.623 & 0.97 \\
\hline 27 & 1,2-dihydroxybenzene & 9.356 & 10.487 & 12.09 & 9.456 & 1.07 \\
\hline 28 & 1,4-dihydroxy-2,6-dinitrobenzene & 4.42 & 2.184 & -50.59 & 4.425 & 0.11 \\
\hline 29 & 1,3-dihydroxy-2-methylbenzene & 10.05 & 9.685 & -3.63 & 9.603 & -4.45 \\
\hline 30 & 1,2-dihydroxy-3-nitrobenzene & 6.68 & 3.728 & -44.19 & 6.68 & 0.00 \\
\hline 31 & 1,2-dihydroxy-4-nitrobenzene & 6.701 & 8.082 & 20.61 & 6.824 & 1.84 \\
\hline 32 & 3,5-diiodophenol & 8.103 & 6.653 & -17.89 & 8.126 & 0.28 \\
\hline 33 & 3,5-dimethoxyphenol & 9.345 & 9.32 & -0.27 & 9.497 & 1.63 \\
\hline 34 & 2,6-dimethyl-4-nitrophenol & 7.190 & 7.736 & 7.59 & 7.439 & 3.46 \\
\hline 35 & 3,5-dimethyl-4-nitrophenol & 8.245 & 8.131 & -1.38 & 8.299 & 0.65 \\
\hline 36 & 2,3-dimethylphenol & 10.50 & 10.117 & -3.65 & 10.246 & -2.42 \\
\hline 37 & 2,6-dimethylphenol & 10.59 & 9.824 & -7.23 & 10.264 & -3.08 \\
\hline 38 & 3,4-dimethylphenol & 10.32 & 10.055 & -2.57 & 10.298 & -0.21 \\
\hline 39 & 3,5-dimethylphenol & 10.15 & 10.113 & -0.36 & 10.068 & -0.81 \\
\hline 40 & 2,4-dinitrophenol & 4.08 & 6.75 & 65.44 & 4.081 & 0.02 \\
\hline 41 & 2,5-dinitrophenol & 5.216 & 6.568 & 25.92 & 5.222 & 0.12 \\
\hline 42 & 3,5-dinitrophenol & 6.732 & 5.961 & -11.45 & 6.658 & -1.10 \\
\hline 43 & 2-ethoxyphenol & 10.109 & 10.886 & 7.69 & 10.117 & 0.08 \\
\hline 44 & 3-ethoxyphenol & 9.655 & 9.801 & 1.51 & 9.617 & -0.39 \\
\hline 45 & 2-ethylphenol & 10.2 & 10.221 & 0.21 & 10.28 & 0.78 \\
\hline 46 & 2-fluorophenol & 8.73 & 9.247 & 5.92 & 9.112 & 4.38 \\
\hline 47 & 3-fluorophenol & 9.29 & 9.072 & -2.35 & 9.16 & -1.40 \\
\hline 48 & 4-fluorophenol & 9.89 & 9.078 & -8.21 & 9.992 & 1.03 \\
\hline 49 & 2'-hydroxyacetophenone & 9.90 & 8.906 & -10.04 & 9.232 & -6.75 \\
\hline 50 & 3'-hydroxyacetophenone & 9.19 & 9.114 & -0.83 & 9.46 & 2.94 \\
\hline 51 & 3-hydroxybenzaldehyde & 9.00 & 8.799 & -2.23 & 9.25 & 2.78 \\
\hline 52 & 4-hydroxybenzaldehyde & 7.620 & 8.423 & 10.54 & 7.96 & 4.46 \\
\hline
\end{tabular}


Table 3. Continued

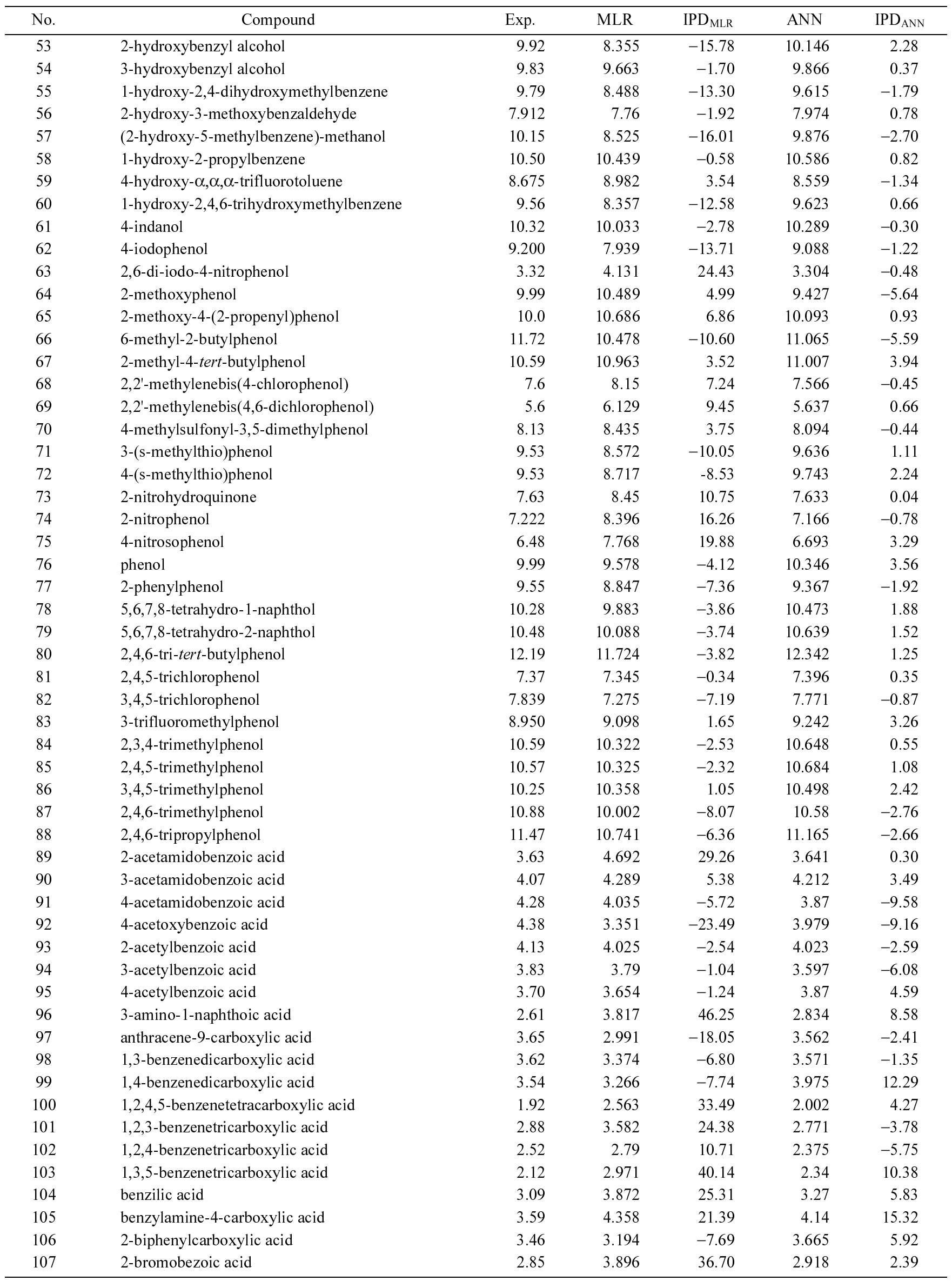


Table 3. Continued

\begin{tabular}{|c|c|c|c|c|c|c|}
\hline No. & Compound & Exp. & MLR & IPD ${ }_{M L R}$ & ANN & $\mathrm{IPD}_{\mathrm{ANN}}$ \\
\hline 108 & 3-bromobezoic acid & 3.810 & 3.065 & -19.55 & 3.915 & 2.76 \\
\hline 109 & 3-tert-butylbenzoic acid & 4.199 & 5.079 & 20.96 & 4.418 & 5.22 \\
\hline 110 & 4-tert-butylbenzoic acid & 4.389 & 4.985 & 13.58 & 4.104 & -6.49 \\
\hline 111 & 2-chlorobenzoic acid & 2.877 & 3.287 & 14.25 & 3.086 & 7.26 \\
\hline 112 & 3-chlorobenzoic acid & 3.83 & 3.319 & -13.34 & 3.698 & -3.45 \\
\hline 113 & 2-chloro-4-nitrobenzoic acid & 1.96 & 1.619 & -17.40 & 1.868 & -4.69 \\
\hline 114 & 2-chloro-5-nitrobenzoic acid & 2.17 & 1.654 & -23.78 & 1.929 & -11.11 \\
\hline 115 & 2-chloro-6-nitrobenzoic acid & 1.342 & 2.153 & 60.43 & 1.417 & 5.59 \\
\hline 116 & 2-cyanobenzoic acid & 3.14 & 2.809 & -10.54 & 2.962 & -5.67 \\
\hline 117 & 3,5-diaminobenzoic acid & 5.30 & 4.731 & -10.74 & 5.225 & -1.42 \\
\hline 118 & 3,6-dichlorophthalic acid & 1.46 & 3.287 & 125.14 & 1.271 & -12.95 \\
\hline 119 & 2,4-dihydroxybenzoic acid & 3.29 & 3.956 & 20.24 & 3.639 & 10.61 \\
\hline 120 & 2,5-dihydroxybenzoic acid & 2.97 & 3.802 & 28.01 & 3.408 & 14.75 \\
\hline 121 & 3,5-dihydroxybenzoic acid & 4.04 & 3.911 & -3.19 & 3.805 & -5.82 \\
\hline 122 & 2,6-dimethoxybenzoic acid & 3.44 & 5.312 & 54.42 & 3.447 & 0.20 \\
\hline 123 & 2,3-dimethylbenzoic acid & 3.771 & 4.55 & 20.66 & 3.668 & -2.73 \\
\hline 124 & 2,4-dimethylbenzoic acid & 4.217 & 4.499 & 6.69 & 4.019 & -4.70 \\
\hline 125 & 2,5-dimethylbenzoic acid & 3.990 & 4.522 & 13.33 & 3.799 & -4.79 \\
\hline 126 & 3,5-dimethylbenzoic acid & 4.302 & 4.467 & 3.84 & 4.189 & -2.63 \\
\hline 127 & 2,3-dimethylnaphthalene-1-carboxylic acid & 3.33 & 4.439 & 33.30 & 3.532 & 6.07 \\
\hline 128 & 2,3-dinitrobenzoic acid & 1.85 & 2.331 & 26.00 & 2.258 & 22.05 \\
\hline 129 & 2,4-dinitrobenzoic acid & 1.43 & 0.688 & -51.89 & 1.587 & 10.98 \\
\hline 130 & 2,5-dinitrobenzoic acid & 1.62 & 1.12 & -30.86 & 1.905 & 17.59 \\
\hline 131 & 3,5-dinitrobenzoic acid & 2.85 & 1.127 & -60.46 & 2.681 & -5.93 \\
\hline 132 & 2-ethylbenzoic acid & 3.79 & 4.575 & 20.71 & 3.757 & -0.87 \\
\hline 133 & 4-ethylbenzoic acid & 4.35 & 4.451 & 2.32 & 4.2 & -3.45 \\
\hline 134 & 2-fluorobenzoic acid & 3.27 & 3.629 & 10.98 & 3.67 & 12.23 \\
\hline 135 & 3-fluorobenzoic acid & 3.865 & 3.586 & -7.22 & 3.584 & -7.27 \\
\hline 136 & 3-hydroxybenzoic acid & 4.076 & 3.993 & -2.04 & 4.496 & 10.30 \\
\hline 137 & 4-hydroxybenzoic acid & 4.582 & 3.912 & -14.62 & 4.627 & 0.98 \\
\hline 138 & 2-hydroxy-5-bromobenzoic acid & 2.61 & 3.096 & 18.62 & 2.722 & 4.29 \\
\hline 139 & 2-hydroxy-5-chlorobenzoic acid & 2.63 & 3.342 & 27.07 & 3.394 & 29.05 \\
\hline 140 & 4-hydroxy-3-methoxybenzoic acid & 4.355 & 3.803 & -12.68 & 4.022 & -7.65 \\
\hline 141 & 2-hydroxy-5-methylbenzoic acid & 4.08 & 4.275 & 4.78 & 3.365 & -17.52 \\
\hline 142 & 2-hydroxy-6-methylbenzoic acid & 3.32 & 5.268 & 58.67 & 3.231 & -2.68 \\
\hline 143 & 2-hydroxy-3-nitrobenzoic acid & 1.87 & 2.427 & 29.79 & 1.93 & 3.21 \\
\hline 144 & 2-hydroxy-5-nitrobenzoic acid & 2.12 & 2.435 & 14.86 & 2.059 & -2.88 \\
\hline 145 & 2-hydroxy-6-nitrobenzoic acid & 2.24 & 2.774 & 23.84 & 2.723 & 21.56 \\
\hline 146 & 4-iodobenzoic acid & 4.00 & 2.59 & -35.25 & 4.162 & 4.05 \\
\hline 147 & mesitylenic acid & 4.32 & 4.467 & 3.40 & 4.189 & -3.03 \\
\hline 148 & 2-methoxybenzoic acid & 4.09 & 4.146 & 1.37 & 3.963 & -3.11 \\
\hline 149 & 3-methoxybenzoic acid & 4.08 & 4.006 & -1.81 & 4.305 & 5.51 \\
\hline 150 & 3-methylbenzoic acid & 4.269 & 4.282 & 0.30 & 4.303 & 0.80 \\
\hline 151 & 4-methylbenzoic acid & 4.362 & 4.214 & -3.39 & 4.541 & 4.10 \\
\hline 152 & 2-methyl-3,5-dinitrobenzoic acid & 2.97 & 1.552 & -47.74 & 2.982 & 0.40 \\
\hline 153 & 2-methyl-1-naphthoic acid & 3.11 & 3.509 & 12.83 & 3.135 & 0.80 \\
\hline 154 & 3-methylsulfonylbenzoic acid & 3.52 & 3.113 & -11.56 & 3.581 & 1.73 \\
\hline 155 & 4-methylsulfonylbenzoic acid & 3.64 & 3.062 & -15.88 & 3.323 & -8.71 \\
\hline 156 & 1-naphthalenecarboxylic acid & 3.695 & 3.68 & -0.41 & 3.938 & 6.58 \\
\hline 157 & 2-naphthalenecarboxylic acid & 4.161 & 3.214 & -22.76 & 3.693 & -11.25 \\
\hline 158 & 4-nitrobenzene-1,2-dicarboxylic acid & 2.11 & 1.933 & -8.39 & 1.917 & -9.15 \\
\hline 159 & 2-nitrobenzoic acid & 2.18 & 2.444 & 12.11 & 2.429 & 11.42 \\
\hline 160 & 3-nitrobenzoic acid & 3.46 & 2.38 & -31.21 & 3.196 & -7.63 \\
\hline 161 & 4-nitrobenzoic acid & 4.441 & 2.295 & -48.32 & 3.286 & -26.01 \\
\hline 162 & $o$-phthalic acid & 2.950 & 3.361 & 13.93 & 2.555 & -13.39 \\
\hline
\end{tabular}


Table 3. Continued

\begin{tabular}{|c|c|c|c|c|c|c|}
\hline No. & Compound & Exp. & MLR & IPD ${ }_{M L R}$ & ANN & $\mathrm{IPD}_{\mathrm{ANN}}$ \\
\hline 163 & 3-sulfamylbenzoic acid & 3.54 & 3.209 & -9.35 & 3.73 & 5.37 \\
\hline 164 & 4-sulfamylbenzoic acid & 3.47 & 3.159 & -8.96 & 3.324 & -4.21 \\
\hline 165 & 2,3,5,6-tetramethylbenzoic acid & 3.415 & 5.746 & 68.26 & 3.401 & -0.41 \\
\hline 166 & 2,4,6-tribromobenzoic acid & 1.41 & 2.063 & 46.31 & 1.408 & -0.14 \\
\hline 167 & 3,4,5-trihydroxybenzoic acid & 4.19 & 3.528 & -15.80 & 3.824 & -8.74 \\
\hline \multirow[t]{2}{*}{168} & 2,4,6-trimethylbenzoic acid & 3.448 & 5.211 & 51.13 & 3.641 & 5.60 \\
\hline & Validation set & & & & & \\
\hline 169 & 2-bromophenol & 8.452 & 8.691 & 2.83 & 8.673 & 2.61 \\
\hline 170 & 2,4-di-tert-butylphenol & 11.64 & 11.741 & 0.87 & 11.887 & 2.12 \\
\hline 171 & 4-chloro-2,6-dinitrophenol & 2.97 & 1.531 & -48.45 & 2.959 & -0.37 \\
\hline 172 & $m$-cresol & 10.00 & 9.835 & -1.65 & 10.017 & 0.17 \\
\hline 173 & 1,3-dichloro-2,5-dihydroxybenzene & 7.30 & 7.295 & -0.07 & 7.066 & -3.21 \\
\hline 174 & 3,4-dichlorophenol & 8.630 & 8.014 & -7.14 & 8.343 & -3.33 \\
\hline 175 & 1,3-dihydroxybenzene & 9.44 & 9.497 & 0.60 & 9.415 & -0.26 \\
\hline 176 & 2,4-dimethylphenol & 10.58 & 10.069 & -4.83 & 10.367 & -2.01 \\
\hline 177 & 2,6-dinitrophenol & 3.713 & 2.105 & -43.31 & 3.718 & 0.13 \\
\hline 178 & 3-ethylphenol & 10.07 & 10.127 & 0.57 & 10.217 & 1.46 \\
\hline 179 & 4'-hydroxyacetophenone & 8.05 & 8.846 & 9.89 & 8.155 & 1.30 \\
\hline 180 & 4-hydroxybenzyl alcohol & 9.82 & 9.53 & -2.95 & 9.829 & 0.09 \\
\hline 181 & 3-hydroxy-4-methoxybenzaldehyde & 8.889 & 6.87 & -22.71 & 8.744 & -1.63 \\
\hline 182 & 2-iodophenol & 8.464 & 8.042 & -4.99 & 8.505 & 0.48 \\
\hline 183 & 3-methoxyphenol & 9.652 & 9.475 & -1.83 & 9.698 & 0.48 \\
\hline 184 & 3-methylsulfonylphenol & 9.33 & 8.579 & -8.05 & 9.219 & -1.19 \\
\hline 185 & 3-nitrophenol & 8.360 & 7.627 & -8.77 & 8.185 & -2.09 \\
\hline 186 & 4-phenylphenol & 9.55 & 8.554 & -10.43 & 9.647 & 1.02 \\
\hline 187 & 1,2,3-trihydroxybenzene & 9.03 & 8.412 & -6.84 & 8.938 & -1.02 \\
\hline 188 & 2-acetoxybenzoic acid & 3.48 & 3.934 & 13.05 & 3.743 & 7.56 \\
\hline 189 & 4-amino-2-naphthoic acid & 2.89 & 3.547 & 22.73 & 3.028 & 4.78 \\
\hline 190 & 1,2,3,4-benzenetetracarboxylic acid & 2.05 & 3.004 & 46.54 & 2.064 & 0.68 \\
\hline 191 & benzoic acid & 4.204 & 4.015 & -4.50 & 4.297 & 2.21 \\
\hline 192 & 4-bromobezoic acid & 3.99 & 2.879 & -27.84 & 4.057 & 1.68 \\
\hline 193 & 4-chlorobenzoic acid & 3.986 & 3.234 & -18.87 & 3.88 & -2.66 \\
\hline 194 & 3-cyanobenzoic acid & 3.60 & 2.725 & -24.31 & 3.381 & -6.08 \\
\hline 195 & 3,4-dihydroxybenzoic acid & 4.48 & 3.758 & -16.12 & 4.153 & -7.30 \\
\hline 196 & 2,6-dimethylbenzoic acid & 3.362 & 4.656 & 38.49 & 3.486 & 3.69 \\
\hline 197 & 2,6-dinitrobenzoic acid & 1.14 & 2.051 & 79.91 & 1.103 & -3.25 \\
\hline 198 & 4-fluorobenzoic acid & 4.14 & 3.573 & -13.70 & 3.854 & -6.91 \\
\hline 199 & 2-hydroxy-3-methylbenzoic acid & 2.99 & 4.336 & 45.02 & 3.376 & 12.91 \\
\hline 200 & 2-iodobenzoic acid & 2.86 & 3.547 & 24.02 & 2.922 & 2.17 \\
\hline 201 & 4-methoxybenzoic acid & 4.49 & 3.91 & -12.92 & 4.456 & -0.76 \\
\hline 202 & 2-methyl-4-nitrobenzoic acid & 1.86 & 2.746 & 47.63 & 2.968 & 59.57 \\
\hline 203 & 2-nitrobenzene-1,4-dicarboxylic acid & 1.73 & 1.981 & 14.51 & 1.953 & 12.89 \\
\hline 204 & 2-phenoxybenzoic acid & 3.53 & 3.36 & -4.82 & 3.758 & 6.46 \\
\hline \multirow[t]{2}{*}{205} & 2,4,6-trihydroxybenzoic acid & 1.68 & 1.793 & 6.73 & 1.793 & 6.73 \\
\hline & Prediction set & & & & & \\
\hline 206 & 3-bromophenol & 9.031 & 8.378 & -7.23 & 9.17 & 1.54 \\
\hline 207 & 2,6-di-tert-butylphenol & 11.7 & 11.053 & -5.53 & 11.895 & 1.67 \\
\hline 208 & 4-chloro-3-methylphenol & 9.549 & 9.111 & -4.59 & 9.593 & 0.46 \\
\hline 209 & $p$-cresol & 10.26 & 9.774 & -4.74 & 10.216 & -0.43 \\
\hline 210 & 2,3-dichlorophenol & 7.44 & 8.196 & 10.16 & 7.827 & 5.20 \\
\hline 211 & 3,5-dichlorophenol & 8.179 & 7.873 & -3.74 & 8.198 & 0.23 \\
\hline 212 & 1,4-dihydroxybenzene & 9.91 & 9.613 & -3.00 & 10.153 & 2.45 \\
\hline 213 & 1,4-dihydroxy-2,3,5,6-tetramethylbenzene & 11.25 & 10.3 & -8.44 & 10.723 & -4.68 \\
\hline
\end{tabular}


Table 3. Continued

\begin{tabular}{|c|c|c|c|c|c|c|}
\hline No. & Compound & Exp. & MLR & IPD $D_{M L R}$ & ANN & $\mathrm{IPD}_{\mathrm{ANN}}$ \\
\hline 214 & 2,5-dimethylphenol & 10.22 & 10.115 & -1.03 & 10.31 & 0.88 \\
\hline 215 & 3,4-dinitrophenol & 5.424 & 7.121 & 31.29 & 5.319 & -1.94 \\
\hline 216 & 4-ethylphenol & 10.0 & 10.064 & 0.64 & 10.293 & 2.93 \\
\hline 217 & 2-hydroxybenzaldehyde & 8.34 & 9.833 & 17.90 & 8.155 & -2.22 \\
\hline 218 & 4-hydroxybenzonitrile & 7.95 & 7.911 & -0.49 & 8.166 & 2.72 \\
\hline 219 & 4-hydroxy-3-methoxybenzaldehyde & 7.396 & 7.974 & 7.82 & 7.896 & 6.76 \\
\hline 220 & 3-iodophenol & 8.879 & 8.099 & -8.78 & 8.921 & 0.47 \\
\hline 221 & 4-methoxyphenol & 10.20 & 9.587 & -6.01 & 10.282 & 0.80 \\
\hline 222 & 4-methylsulfonylphenol & 7.83 & 7.936 & 1.35 & 7.647 & -2.34 \\
\hline 223 & 4-nitrophenol & 7.150 & 7.232 & 1.15 & 7.219 & 0.97 \\
\hline 224 & 3-phenylphenol & 9.63 & 8.485 & -11.89 & 9.671 & 0.43 \\
\hline 225 & 1,3,5-trihydroxybenzene & 8.45 & 8.929 & 5.67 & 8.107 & -4.06 \\
\hline 226 & 3-acetoxybenzoic acid & 4.00 & 3.47 & -13.25 & 3.822 & -4.45 \\
\hline 227 & anthracene-2-carboxylic acid & 4.18 & 2.148 & -48.61 & 4.186 & 0.14 \\
\hline 228 & 1,2,3,5-benzenetetracarboxylic acid & 2.38 & 1.625 & -31.72 & 2.379 & -0.04 \\
\hline 229 & 2-benzoylbenzoic acid & 3.54 & 3.223 & -8.95 & 3.185 & -10.03 \\
\hline 230 & 2-bromo-6-nitrobenzoic acid & 1.37 & 2.004 & 46.28 & 0.957 & -30.15 \\
\hline 231 & 2-chloro-3-nitrobenzoic acid & 2.02 & 2.266 & 12.18 & 2.536 & 25.54 \\
\hline 232 & 4-cyanobenzoic acid & 3.55 & 2.619 & -26.23 & 3.873 & 9.10 \\
\hline 233 & 2,6-dihydroxybenzoic acid & 1.30 & 2.864 & 120.31 & 1.084 & -16.62 \\
\hline 234 & 3,4-dimethylbenzoic acid & 4.41 & 4.471 & 1.38 & 4.255 & -3.51 \\
\hline 235 & 3,4-dinitrobenzoic acid & 2.82 & 2.251 & -20.18 & 2.738 & -2.91 \\
\hline 236 & 2-hydroxybenzoic acid & 2.98 & 4.091 & 37.28 & 3.313 & 11.17 \\
\hline 237 & 2-hydroxy-4-methylbenzoic acid & 3.17 & 4.308 & 35.90 & 3.128 & -1.32 \\
\hline 238 & 3-iodobenzoic acid & 3.86 & 2.771 & -28.21 & 3.529 & -8.58 \\
\hline 239 & 2-methylbenzoic acid & 3.90 & 4.357 & 11.72 & 3.749 & -3.87 \\
\hline 240 & 2-methyl-6-nitrobenzoic acid & 1.87 & 4.44 & 137.43 & 1.939 & 3.69 \\
\hline 241 & 3-nitrobenzene-1,2-dicarboxylic acid & 1.88 & 2.334 & 24.15 & 1.872 & -0.43 \\
\hline 242 & 4-phenoxybenzoic acid & 4.52 & 3.194 & -29.34 & 3.993 & -11.66 \\
\hline
\end{tabular}

${ }^{a}$ Exp. refers to the experimental values of $\mathrm{pKa}$, MLR and ANN refer to multi-parameter linear regression and artificial neural network calculated values of $\mathrm{pKa}$, respectively.

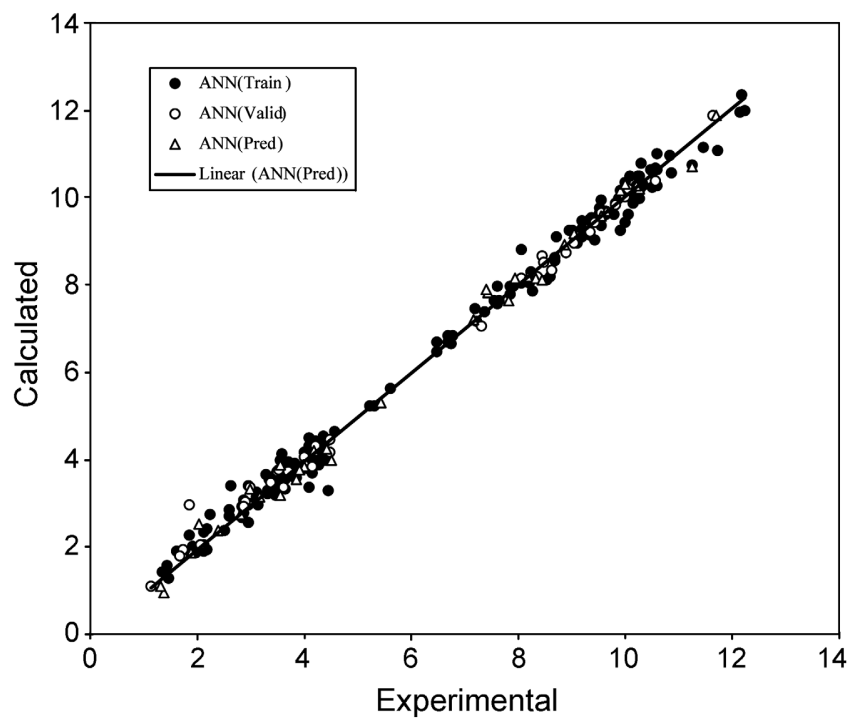

Figure 4. Plot of the calculated values of $\mathrm{pKa}$ from the ANN model versus the experimental values of it for training, validation and prediction sets.

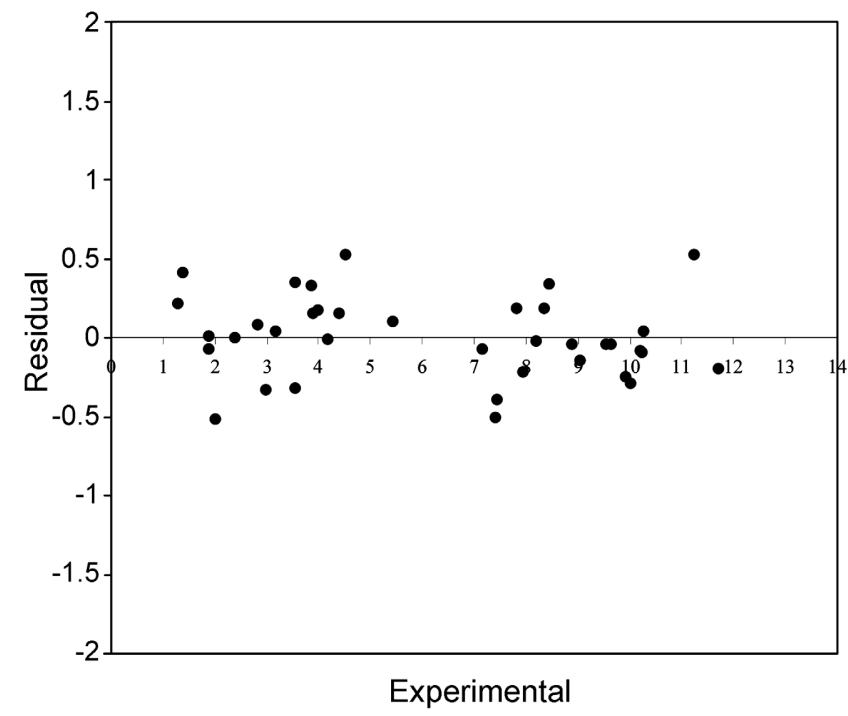

Figure 5. Plot of the residual for calculated values of $\mathrm{pKa}$ from the ANN model versus the experimental values of it for prediction set. 
Table 4. Comparsion of statistical parameters obtained by the MLR and ANN models for correlation acidity constant of phenols and benzoic acids with the molecular descriptors ${ }^{a}$

\begin{tabular}{ccccccccc}
\hline Model & $\mathrm{R}_{\text {tot }}^{2}$ & $\mathrm{R}_{\text {train }}^{2}$ & $\mathrm{R}_{\text {valid }}^{2}$ & $\mathrm{R}_{\text {pred }}^{2}$ & $\mathrm{RMSE}_{\text {tot }}$ & $\mathrm{RMSE}_{\text {train }}$ & $\mathrm{RMSE}_{\text {valid }}$ & $\mathrm{RMSE}_{\text {pred }}$ \\
\hline MLR & 0.9266 & 0.9268 & 0.9400 & 0.9147 & 0.8610 & 0.8553 & 0.8034 & 0.9388 \\
ANN & 0.9931 & 0.9926 & 0.9943 & 0.9939 & 0.2648 & 0.2700 & 0.2479 & 0.2575 \\
\hline
\end{tabular}

${ }^{a}$ Subscript train is referring to the training set, valid is referring to the validation set and pred is referring to the prediction set, tot is refering to the total data set and $\mathrm{R}$ is the correlation coefficient.

\section{Conclusions}

A linear and non-linear QSPR models have been developed for prediction of acidity constant $(\mathrm{pKa})$ for various benzoic acids and phenols in water. Comparison of the values of RMSE for training, validation and prediction sets (and other statistical parameters in Table 4) for the MLR and ANN models show superiority of the nonlinear model over the regression model. Root-mean square error of 0.9388 for the prediction set by the MLR model should be compared with the value of 0.25751 for the ANN model. Since the improvement of the results obtained using nonlinear model (ANN) is considerable, it can be concluded that the nonlinear characteristics of the molecular descriptors on the $\mathrm{pKa}$ values of the compounds in water is serious.

Acknowledgements. The Authors wish to acknowledge the vice-presidency of research, university of Mohaghegh Ardebili, for financial support of this work.

\section{References}

1. Katritzky, A. R.; Karelson, M.; Lobanov, V. S. Pure Appl. Chem. 1997, 69, 245.

2. Balaban, A. T. J. Chem. Inf. Comut. Sci. 1997, 37, 645.

3. Benfenati, E.; Gini, G. Toxicology 1997, 119, 213.

4. Cronce, D. T.; Famini, G. R.; Soto, J. A. D.; Wilson, L. Y. J. Chem. Soc., Perkin Trans. 2 1998, 1293.

5. Engberts, J. B. F. N.; Famini, G. R.; Perjessy, A.; Wilson, L. Y. J. Phys. Org. Chem. 1998, 11, 261.

6. Hiob, R.; Karelson, M. J. Chem. Inf. Comut. Sci. 2000, 40, 1062 .

7. Habibi-Yangjeh, A. Indian J. Chem. 2003, 42B, 1478.

8. Habibi-Yangjeh, A. Indian J. Chem. 2004, 43B, 1504.

9. Nikolic, S.; Milicevic, A.; Trinajstic, N.; Juric, A. Molecules 2004, 9, 1208.

10. Devillers, J. SAR and QSAR Environ. Res. 2004, 15, 501.

11. Karelson, M.; Lobanov, V. S. Chem. Rev. 1996, 96, 1027.

12. Todeschini, R.; Consonni, V. Handbook of Molecular Descriptors; Wiley-VCH: Weinheim, Germany, 2000.

13. Kramer, R. Chemometric Techniques for Quantitative Analysis; Marcel Dekker: New York, 1998.

14. Wold, S.; Sjöström, M. Chemom. Intell. Lab. Syst. 1998, 44, 3.

15. Barros, A. S.; Rutledge, D. N. Chemomet. Intell. Lab. Syst. 1998, 40,65 .

16. Garkani-Nejad, Z.; Karlovits, M.; Demuth, W.; Stimpfl, T.; Vycudilik, W.; Jalali-Heravi, M.; Varmuza, K. J. Chromatogr. A 2004, 1028, 287.

17. Patterson, D. W. Artificial Neural Networks: Theory and Applications; Simon and Schuster: New York, 1996; Part III, Ch. 6.

18. Bose, N. K.; Liang, P. Neural Network Fundamentals; McGrawHill: New York, 1996.
19. Zupan, J.; Gasteiger, J. Neural Networks in Chemistry and Drug Design; Wiley-VCH: Weinhein, 1999.

20. Agatonovic-Kustrin, S.; Beresford, R. J. Pharm. Biomed. Anal. 2000, 22, 717 .

21. Fatemi, M. H. J. Chromatogr. A 2002, 955, 273.

22. Xing, W. L.; He, X. W. Anal. Chim. Acta 1997, 349, 283.

23. Bunz, A. P.; Braun, B.; Janowsky, R. Fluid Phase Equilib. 1999, $158,367$.

24. Homer, J.; Generalis, S. C.; Robson, J. H. Phys. Chem. Chem. Phys. 1999, 1, 4075.

25. Goll, E. S.; Jurs, P. C. J. Chem. Inf. Comp. Sci. 1999, 39, 974.

26. Vendrame, R.; Braga, R. S.; Takahata, Y.; Galvao, D. S. J. Chem. Inf. Comput. Sci. 1999, 39, 1094

27. Gaspelin, M.; Tusar, L.; Smid-Korbar, J.; Zupan, J.; Kristl, J. Int. J. Pharm. 2000, 196, 37.

28. Gini, G.; Cracium, M. V.; Konig, C.; Benfenati, E. J. Chem. Inf. Comput. Sci. 2004, 44, 1897.

29. Urata, S.; Takada, A.; Uchimaru, T.; Chandra, A. K.; Sekiya, A. J. Fluorine Chem. 2002, 116, 163.

30. Koziol, J. Internet Electron J. Mol. Des. 2003, 2, 315.

31. Wegner, J. K.; Zell, A. J. Chem. Inf. Comput. Sci. 2003, 43, 1077.

32. Valkova, I.; Vracko, M.; Basak, S. C. Anal. Chim. Acta 2004, 509, 179.

33. Sebastiao, R. C. O.; Braga, J. P.; Yoshida, M. I. Thermochimica Acta 2004, 412, 107.

34. Jalali-Heravi, M.; Masoum, S.; Shahbazikhah, P. J. Magn. Reson. 2004, 171, 176.

35. Habibi-Yangjeh, A.; Nooshyar, M. Bull. Korean Chem. Soc. 2005, 26, 139.

36. Habibi-Yangjeh, A.; Nooshyar, M. Physics and Chemistry of Liquids 2005, 43, 239.

37. Selassie, C. D.; DeSoyza, T. V.; Rosario, M.; Gao, H.; Hansch, C. Chemico-Biological Interaction 1998, 113, 175.

38. Zhao, Y.-H.; Yuan, L.-H.; Wang, L.-S. Bull. Environ. Contam. Toxicol. 1996, 57, 242.

39. Hemmateenejad, B.; Sharghi, H.; Akhond, M.; Shamsipur, M. J. Solution Chem. 2003, 32, 215.

40. Gruber, C.; Buss, V. Chemosphere 1989, 19, 1595.

41. Citra, M. J. Chemosphere 1999, 38, 191.

42. Schuurmann, G. Quant. Struct. Act. Relat. 1996, 15, 121.

43. Gross, K. C.; Seybold, P. G. Int. J. Quant. Chem. 2001, 85, 569.

44. Liptak, M. D.; Gross, K. C.; Seybold, P. G.; Feldgus, S.; Shields, G. C. J. Am. Chem. Soc. 2002, 124, 6421.

45. Hanai, T.; Koizumi, K.; Kinoshita, T. J. Liq. Chromatogr. Relat. Technol. 2000, 23, 363.

46. Ma, Y.; Gross, K. C.; Hollingsworth, C. A.; Seybold, P. G; Murray, J. S. J. Mol. Model 2004, 10, 235.

47. HyperChem, Release 7.0 for Windows, Molecular Modeling System; Hypercube Inc.: 2002.

48. Todeschini, R.; Consonni, V.; Pavan, M. Dragon Software, Version $2.1 ; 2002$.

49. Dean, J. A. Lange's Handbook of Chemistry, 15th Ed.; McGrawHill, Inc.: 1999.

50. Demuth, H.; Beale, M. Neural Network Toolbox; Mathworks: Natick, MA, 2000.

51. Despagne, F.; Massart, D. L. Analyst 1998, 123, 157R.

52. Matlab 6.5; Mathworks: 1984-2002.

53. Famini, G. R.; Wilson, L. Y. J. Phys. Org. Chem. 1999, 12, 645. 